\title{
ANALYSIS OF MAGNETIC FIELD DISTRIBUTION IN MATRIX OF MAGNETIC SEPARATOR WITH LAMELLAR POLYGRADIENT MEDIUM
}

\author{
Iryna Shvedchykova \\ Department of electrical engineering \\ Volodymyr Dahl East Ukrainian National University \\ 59-a Central ave., Severodonetsk, Ukraine, 93400 \\ ishved@i.ua \\ Julia Romanchenko \\ Department of electrical engineering \\ Volodymyr Dahl East Ukrainian National University \\ 59-a Central ave., Severodonetsk, Ukraine, 93400 \\ romanchenkojulia@i.ua \\ Inna Nikitchenko \\ Department of electrical engineering \\ Volodymyr Dahl East Ukrainian National University \\ 59-a Central ave., Severodonetsk, Ukraine, 93400 \\ inna.mia.lg@gmail.com
}

\begin{abstract}
The distribution of the magnetic field in the working zones of synthesized polygradient media is studied using a computational experiment. The distribution of the magnetic field is carried out by the numerical finite element method, realized with the help of the ELCUT program complex. It is substantiated that instead of studying the field distribution in the entire interpolar zone of arbitrary structure, it can limited by the field studies in a characteristic, periodically repeating region, taking into account its symmetry. For the studied structural compositions of polygradient media using the ELCUT program tools, two-dimensional geometric models of the working interpolar zones have been developed, taking into account generally accepted engineering assumptions.

A comparative analysis of the distribution of induction and force function of the magnetic field in the working gaps of the synthesized structures of a lamellar polygradient medium of a given configuration is performed.

Keywords: magnetic field, magnetic separator, force function, finite element method, similarity criterion.

\section{Introduction}

In practice, the method of magnetic separation [1], based on the use of differences in the magnetic susceptibility of particles of separated media, has been widely used. The most difficult in this case is the process of extraction from nonmagnetic media of weakly magnetic and finely dispersed ferromagnetic inclusions of micron sizes. To remove such inclusions, various polygradient magnetic separators of the matrix type are used.

A significant influence on the distribution of the force of the magnetic field has a structure of the polygradient medium (shape, mutual arrangement of the ferromagnetic elements) and its geometric dimensions. Thus, the effect of the cross section shape of the magnetic medium elements on the induction distribution and the gradient of the magnetic field of the polygradient separator are investigated in [2]. In this paper it is established that the most powerful and inhomogeneous magnetic field is provided by a polygradient medium based on triangular elements. It is shown in the publication [3] that the arrangement of the rod elements in the matrix has a direct effect on the performance of high-gradient magnetic separation. The results of computer simulation of devices for magnetic separation of human blood flow under natural conditions are given in [4, 5], which allowed to analyze the effect of configurations of elements of magnetic systems on the efficiency of nanoparticle capture. In [6], the significant influence of the characteristic dimensions of the filter elements and the separated particles on the separator's ability to extract is shown.
\end{abstract}


Analysis of literature sources shows that the choice of the polygradient medium structure is carried out mainly empirically. Therefore, systematic research aimed at selecting rational structures and sizes of elements of separator matrices providing the greatest induction and magnetic field gradient in working gaps is relevant.

The aim of this article is a comparative analysis of magnetic field distribution in the working gaps of the synthesized structures of a lamellar polygradient medium of a given configuration.

\section{A systematic approach to the study of polygradient media}

In author's works $[7,8]$, the possibility of applying genetic synthesis and simulation methods to determine the possible structures of polygradient media of magnetic separators is substantiated. The basis of algorithms of genetic synthesis is formed by genetic operators of crossing, replication, mutation and spatial inversion, and the order of application of these operators is represented by the genetic model [9].

In [8], a plate in the form of a rectangular triangle was chosen as the elementary generating element (monostructure) of the polygradient medium. Six structural variants (compositions) $\mathrm{S}_{\mathrm{i}}(\mathrm{i}=1,2 \ldots 6)$ of a lamellar polygradient medium are obtained for the adopted integral objective search function using symmetry operations. They are shown in Table $\mathbf{1 .}$

Table 1

Structural compositions of the lamellar polygradient medium

Code Geometric model Symmetry operation

When analyzing the magnetic fields of separators, the problems are formulated with respect to the vector magnetic potential $\overline{\mathrm{A}}$ (the relation $\overline{\mathrm{A}}=\operatorname{rot} \overline{\mathrm{B}}$ is given, $\overline{\mathrm{B}}-$ the vector of the magnetic field induction). For linear and isotropic media $\left(\mu_{x}=\mu_{y}=\mu_{z}=\mu=\right.$ const), the equation of the magnetic field of the relative vector magnetic potential is Poisson's equation

$$
\nabla^{2} \overline{\mathrm{A}}=-\mu_{\mathrm{a}} \overline{\mathrm{J}}
$$

where $\mu_{\mathrm{a}}$ - the absolute magnetic permeability; $\overline{\mathbf{J}}$ - vector of current density. 
Since in the working gaps of polygradient media there is a condition for the absence of electric currents, to describe the magnetic field, a scalar magnetic potential $\phi_{\mathrm{m}}$ is introduced. It is given by the relation [1]

$$
\overline{\mathrm{H}}=-\operatorname{grad} \phi_{\mathrm{m}}=-\nabla \phi_{\mathrm{m}}
$$

where $\overline{\mathrm{H}}$ - the vector of the magnetic field force in the computational domain, not occupied by electric currents. The use of a scalar magnetic potential $\phi_{\mathrm{m}}$ makes it possible to reduce the problem of determining the distribution of the magnetic field in the working space of polygradient media of magnetic separators to the solution of the Laplace equation

$$
\nabla^{2} \phi_{\mathrm{m}}=0
$$

After finding the scalar potential $\phi_{\mathrm{m}}$, the distribution of the magnetic field force is defined as $\overline{\mathrm{H}}=-\nabla \phi_{\mathrm{m}}$, and the magnetic induction as $\overline{\mathrm{B}}=\mu_{0} \overline{\mathrm{H}}$. The magnitude of the magnetic force $\mathrm{F}_{\mathrm{m}}$ acting on the extracted particles in an inhomogeneous magnetic field is calculated according to the expression [5]

$$
\mathrm{F}_{\mathrm{m}}=\mathrm{V}_{\mathrm{p}} \chi \nabla \frac{|\mathrm{B}|^{2}}{2 \mu_{0}}
$$

where $V_{p}$ - the volume of the particle; $\chi$ - magnetic susceptibility of the particle material.

In expression (3), the vector function $G(r)$ of the point of space $r$ is numerically equal to the magnetic force acting on a particle of unit volume with a single magnetic susceptibility located at this point [5],

$$
\mathrm{G}(\mathrm{r})=\nabla\left|\mathrm{B}_{0}\right|^{2} / 2 \mu_{0}
$$

The function $G(r)$ is called the force function of the inhomogeneous magnetic field and is its intrinsic characteristic.

In the present article, the solution of (2) was performed by a numerical finite element method, realized with the help of the ELCUT program complex [10].

\section{Calculation of the magnetic field distribution in the working interpolar volumes of the syn- thesized structures of the polygradient medium}

At this stage, experimental studies were carried out for two variants of synthesized structures $\mathrm{S}_{1}$ and $\mathrm{S}_{3}$, which are of the greatest practical interest. As an analysis of information sources has shown $[1,2,6]$, these structures are widely used in filter matrices of polygradient separators, for example, in a rotary separator of the Jones type (Table 2).

The working interpolar zones of the $\mathrm{S}_{1}, \mathrm{~S}_{3}$ structures are distinguished by the repetitiveness of the characteristic geometrically similar regions, for which symmetry lines (ff' and ee' in Table 2) can be distinguished. Therefore, instead of studying the field distribution in the entire interpolar zone of an arbitrary Si structure, it can limited by the field studies in a characteristic, periodically repeating region, taking into account its symmetry. Table 2 also gives the magnetic models of characteristic regions for two structures $\left(\mathrm{S}_{1}, \mathrm{~S}_{3}\right)$, where the following designations are adopted:

$\delta$ - an interpolar working gap corresponding to the minimum distance between the plates;

$\alpha$ - the angle at the tip of the pole projection;

$\mathrm{b}$ - the base of the pole projection;

$\mathrm{a}$ - the working width of the matrix.

For the studied structural compositions $\mathrm{S}_{\mathrm{i}}$ of polygradient media using the tools of the ELCUT program, two-dimensional geometric models of the working interpolar zones have been developed, taking into account generally accepted in engineering practice assumptions: 
1. The distribution of the magnetic field within the working interpolar zones is plane-parallel.

2. The surfaces of the poles are equipotential, which is valid with sufficient accuracy for small values of the magnetic induction in the steel of the poles, as is the case in reality.

3. The influence on the field distribution of the geometry of the cores and magnetizing coils is negligible and can be neglected.

To analyze the effect of the geometry of the structures $\mathrm{S}_{1}, \mathrm{~S}_{3}$ on the field distribution, seven most characteristic (similar) points in the working zones are chosen, located along the rays passing through the centers of air gaps (points 1-7, Fig. 1).

Table 2

Magnetic models of working interpolar zones
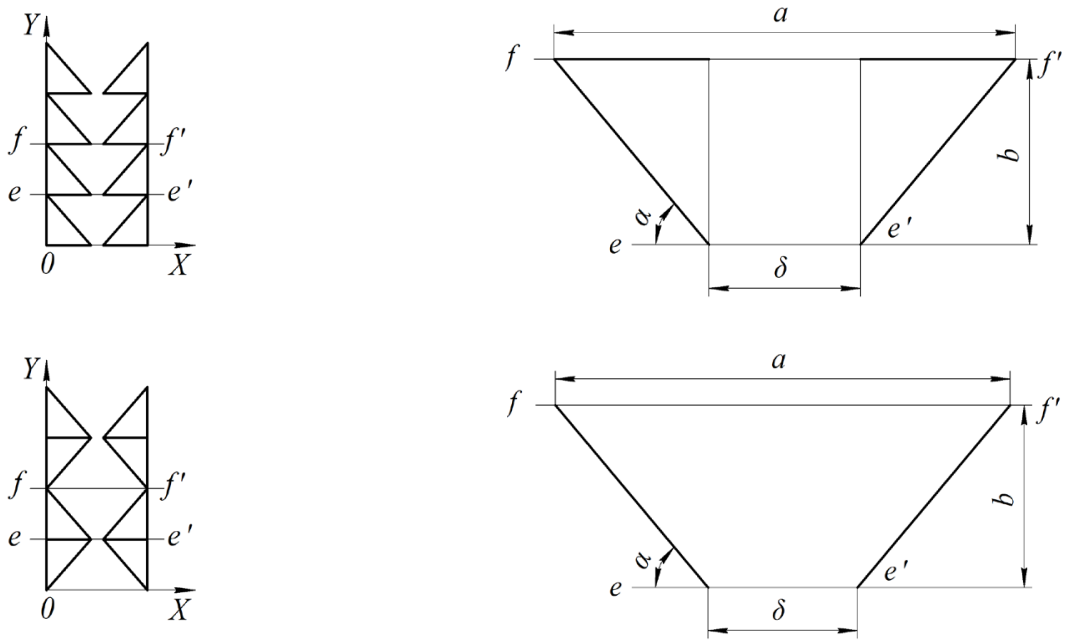

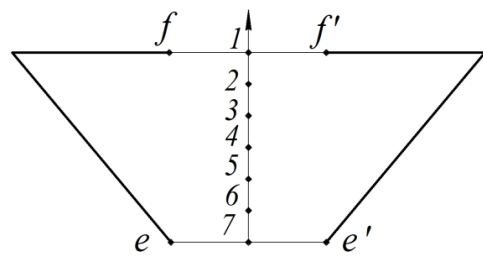

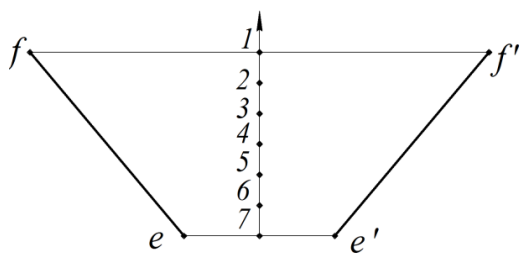

$b$

Fig. 1. The location of the characteristic points: $a$ - for the structure $\mathrm{S}_{1}, b$ - for the structure $\mathrm{S}_{3}$

The following geometric similarity criteria were determined for the investigated regions: $X_{1}=b / a$ and $X_{2}=\alpha$. The ranges of variation of the geometric similarity criteria $X_{1}$ and $X_{2}$, which are of practical interest, are: $X_{1}=b / a=0,2 \ldots 0,4 ; X_{2}=\alpha=0,22 \pi \ldots 0,44 \pi$. To describe the physical properties of the problem, boundary conditions were set taking into account the fact that the relative magnetic permeability of air is $\mu=1$.

The air design area (Fig. 1) is limited by the contour ff'ee':

$\mathrm{ff}^{\prime}$ - the line of force for which the vector magnetic potential $\overline{\mathrm{A}}=0$ (the Dirichlet condition). Such boundary condition is used to indicate the total attenuation of the field at a remote boundary;

$\mathrm{ee}^{\prime}$ - the line of force, on which the Dirichlet boundary condition is also defined, which determines the behavior of the normal component of the magnetic induction at the boundary. In the general Dirichlet case, the value of the vector potential in the section ee' is given arbitrarily. During the experiment, the value $\mathrm{A}=0.0365 \mathrm{~Wb} / \mathrm{m}$ was adopted (based on the experience of designing similar devices); 
fe, $\mathrm{f}^{\prime} \mathrm{e}^{\prime}-$ the boundaries corresponding to the steel surfaces $\mathrm{H}_{\mathrm{t}}=0$ (homogeneous Neumann condition). Such boundary condition is natural, because it is installed by default on all those sides that make up the external boundary, where the boundary condition is not explicitly specified otherwise.

Further, the spatial configuration of the magnetic field in the working gaps of the synthesized structures is determined. The results of simulation (magnetic field pattern) are shown in Fig. 2.

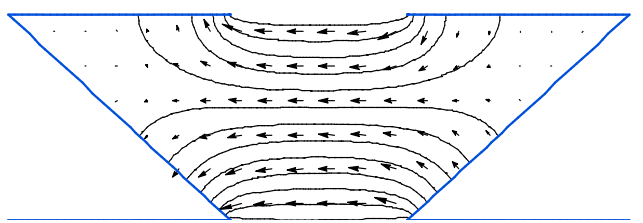

$a$

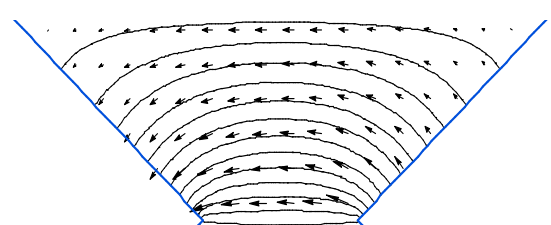

$b$

Fig. 2. The simulation results for $\mathrm{b} / \mathrm{a}=0,3$ and $\alpha=40^{\circ}$ : $a$ - for the structure $\mathrm{S}_{1}, b-$ for the structure $\mathrm{S}_{3}$

The magnetic induction of the field along the ray passing through the center of the air gap (points 1-7, Fig. 1) was measured in the work. Calculation of the force function $\mathrm{G}_{\mathrm{i}}(\mathrm{r})$ at similar points was carried out according to the formula (4).

\section{Comparative analysis of the results of calculating the magnetic field distribution}

As a result of the conducted studies it was established that at $X_{2}>40^{\circ}=0,22 \pi$ the magnetic field in the working interpolar zones of the studied structures is characterized by a high degree of uniformity for any values of $\mathrm{X}_{1}=\mathrm{b} / \mathrm{a}$. Thus, Table 3 shows, for example, the results of measuring the magnetic induction $B$ at similar points in the structures $S_{1}, S_{3}$ at $X_{2}=60=0,33 \pi$. The greatest difference $\Delta \mathrm{B}$ between the maximum $\mathrm{B}_{\max }$ and the minimum $\mathrm{B}_{\min }$ value of the magnetic induction (in relative units) is observed for the structure $\mathrm{S}_{3}$ at $\mathrm{X}_{1}=\mathrm{b} / \mathrm{a}=0,4$ and does not exceed $10 \%$.

Table 3

The results of the measurement of the magnetic induction at the similar points at $\mathrm{X}_{2}=60^{\circ}=0,33 \pi$

\begin{tabular}{|c|c|c|c|c|c|c|c|c|c|c|c|}
\hline \multirow{2}{*}{ Code } & \multirow[b]{2}{*}{$\mathbf{X}_{1}$} & \multicolumn{7}{|c|}{ The magnetic induction $B$ at similar points, $T$} & \multirow[b]{2}{*}{$\mathbf{B}_{\max }, T$} & \multirow[b]{2}{*}{$\mathbf{B}_{\min }, \mathbf{T}$} & \multirow{2}{*}{$\Delta \mathrm{B}, \%$} \\
\hline & & 1 & 2 & 3 & 4 & 5 & 6 & 7 & & & \\
\hline \multirow{3}{*}{$\mathrm{S}_{1}$} & 0,2 & 0,336 & 0,337 & 0,338 & 0,339 & 0,339 & 0,340 & 0,341 & 0,341 & 0,336 & 1,5 \\
\hline & 0,3 & 0,225 & 0,226 & 0,227 & 0,228 & 0,228 & 0,229 & 0,230 & 0,230 & 0,225 & 2,2 \\
\hline & 0,4 & 0,172 & 0,172 & 0,171 & 0,171 & 0,173 & 0,175 & 0,175 & 0,175 & 0,171 & 2,3 \\
\hline \multirow{3}{*}{$\mathrm{S}_{3}$} & 0,2 & 0,337 & 0,337 & 0,338 & 0,338 & 0,338 & 0,338 & 0,339 & 0,339 & 0,337 & 0,6 \\
\hline & 0,3 & 0,220 & 0,221 & 0,223 & 0,225 & 0,229 & 0,230 & 0,231 & 0,231 & 0,220 & 4,8 \\
\hline & 0,4 & 0,158 & 0,159 & 0,161 & 0,168 & 0,176 & 0,182 & 0,174 & 0,174 & 0,158 & 9,2 \\
\hline
\end{tabular}

As follows from (4), in order to obtain the maximum value of the magnetic force $F_{m}$ acting on the extracted ferromagnetic (or weakly magnetic) inclusions, it is necessary to strive to increase the degree of inhomogeneity of the magnetic field in the working zone, i. e. strive to increase the value of the modulus of the vector $\nabla\left|\mathrm{B}_{0}\right|^{2}$. Therefore, the structures $\mathrm{S}_{1}, \mathrm{~S}_{3}$ at $\mathrm{X}_{2}>40^{\circ}=0,22 \pi$ and $\mathrm{X}_{1}=\mathrm{b} / \mathrm{a}=0,2 \ldots 0,4$, which are characterized by an extremely low degree of field inhomogeneity, can be excluded from consideration.

The highest degree of intensity and field inhomogeneity in the test versions of structures $\left(\mathrm{S}_{1}, \mathrm{~S}_{3}\right)$ is observed at $X_{1}=b / a=0,4$ and $X_{2} \leq 40^{\circ}=0,22 \pi$. As an example, Table 4 shows the results of mea- 
surement of the magnetic induction $B$ in the similar points of structures when $X_{2}=40^{\circ}=0,22 \pi$. For structures $\mathrm{S}_{1}, \mathrm{~S}_{3}$, the degree of field inhomogeneity at $\mathrm{X}_{1}=\mathrm{b} / \mathrm{a}=0,4$ was 77,7 and $88 \%$, respectively.

Table 4

The results of the measurement of the magnetic induction at the similar points at $X_{2}=40^{\circ}=0,22 \pi$

\begin{tabular}{|c|c|c|c|c|c|c|c|c|c|c|c|}
\hline \multirow{2}{*}{ Code } & \multirow{2}{*}{$\mathbf{X}_{1}$} & \multicolumn{7}{|c|}{ The magnetic induction $B$ at similar points, $T$} & \multirow{2}{*}{$\mathbf{B}_{\max }, \mathbf{T}$} & \multirow{2}{*}{$\mathbf{B}_{\min }, \mathbf{T}$} & \multirow{2}{*}{$\Delta \mathrm{B}, \%$} \\
\hline & & 1 & 2 & 3 & 4 & 5 & 6 & 7 & & & \\
\hline \multirow{3}{*}{$\mathrm{S}_{1}$} & 0,2 & 0,335 & 0,338 & 0,340 & 0,342 & 0,343 & 0,345 & 0,345 & 0,345 & 0,335 & 2,9 \\
\hline & 0,3 & 0,244 & 0,238 & 0,229 & 0,227 & 0,234 & 0,245 & 0,248 & 0,248 & 0,227 & 8,5 \\
\hline & 0,4 & 0,440 & 0,158 & 0,103 & 0,100 & 0,127 & 0,218 & 0,449 & 0,449 & 0,100 & 77,7 \\
\hline \multirow{3}{*}{$\mathrm{S}_{3}$} & 0,2 & 0,333 & 0,334 & 0,336 & 0,338 & 0,340 & 0,342 & 0,343 & 0,343 & 0,333 & 2,9 \\
\hline & 0,3 & 0,187 & 0,190 & 0,201 & 0,219 & 0,243 & 0,266 & 0,277 & 0,277 & 0,187 & 32,5 \\
\hline & 0,4 & 0,074 & 0,077 & 0,087 & 0,108 & 0,151 & 0,266 & 0,617 & 0,617 & 0,074 & 88,0 \\
\hline
\end{tabular}

For the final selection of a rational structure of polygradient medium define the power function $G_{1}(r), G_{3}(r)$ for the structures $S_{1}$ and $S_{3}$ at $X_{1}=b / a=0,3$ and $X_{2}=40^{\circ}=0,22 \pi$. Fig. 3 shows the variation of the $\mathrm{y}$-component of these functions along the active zone of the magnetic system at similar points.

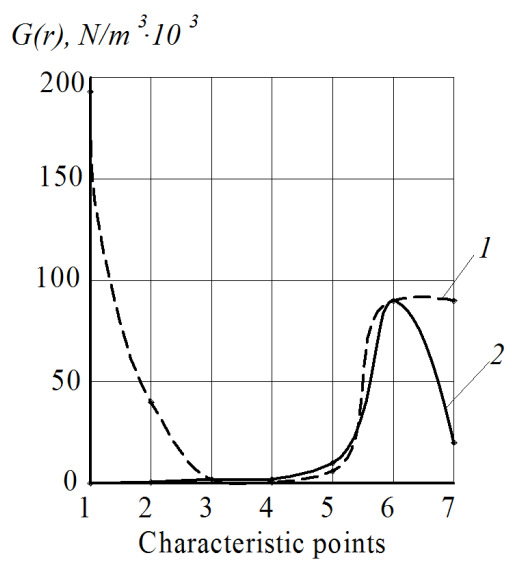

Fig. 3. Change in the $y$-components of the force functions along the core: $1-G_{1}(r) ; 2-G_{3}(r)$

The calculated data in Fig. 3 indicate that the greatest force is localized in the angular zones of the projections, sharply decaying as it moves away from the poles. At the same time, for further research we should recommend the structure $\mathrm{S}_{1}$, which, in comparison with the structure $\mathrm{S}_{3}$, provides both higher values of the force function and twice the number of local zones of a high field gradient.

\section{Conclusions}

Based on the data of the computational experiment, an analysis of the topography of the magnetic field at similar points for two structural variants $\left(\mathrm{S}_{1}, \mathrm{~S}_{3}\right)$ of lamellar polygradient media was carried out. It was found that the highest degree of intensity and field inhomogeneity in the test versions of structures observed at $\mathrm{X}_{1}=\mathrm{b} / \mathrm{a}=0,4$ and $\mathrm{X}_{2} \leq 40^{\circ}=0,22 \pi$. 
An investigation of the distribution of the y-components of the force functions along the active medium zone showed that the structure $S_{1}$, which is characterized by higher power function indices, should be considered rational.

The obtained results make it possible to carry out a detailed comparative analysis of the power characteristics of lamellar polygradient media of given configurations and to determine their efficiency in capturing magnetic inclusions.

In the direction of further research, the authors will propose a generalized approach to the evaluation of the extraction efficiency of magnetic inclusions by polygradient media of arbitrary configurations.

\section{References}

[1] Zagirnyak, M. V., Branspiz, Yu. A., Shvedchikova, I. A. (2011). Magnitnye separatory. Problemy proektirovanija. Kyiv: Tehnika, 224.

[2] Ren, L., Zeng, S., Zhang, Y. (2015). Magnetic field characteristics analysis of a single assembled magnetic medium using ANSYS software. International Journal of Mining Science and Technology, 25 (3), 479-487. doi: 10.1016/j.ijmst.2015.03.024

[3] Chen, L. Z., Xu, G. D., Wen, S. M., Liu, S. Q., Gao, L. K. (2013). Effect of Rod Arrangement in Matrix on High Gradient Magnetic Separation Performance. Advanced Materials Research, 634-638, 3351-3354. doi: 10.4028/www.scientific.net/amr.634-638.3351

[4] Chen, H., Bockenfeld, D., Rempfer, D., Kaminski, M. D., Liu, X., Rosengart, A. J. (2008). Preliminary 3-D analysis of a high gradient magnetic separator for biomedical applications. Journal of Magnetism and Magnetic Materials, 320 (3-4), 279-284. doi: 10.1016/j.jmmm.2007.06.001

[5] Kirilenko, A. V., Chehun, V. F., Podol'cev, A. D., Kondratenko, I. P., Kucherjavaja, I. N., Bondar, V. V., Shpilevaja, S. I., Todor, I. N. (2010). Analiz silovogo vozdejstvija vysokogradientnogo magnitnogo polja na magnitnye nanochasticy v potoke zhidkosti. Dopovidi Nacional'noi' akademii' nauk Ukrai'ny, 9, 162-172.

[6] Tolmachev, S. T., Bondarevskij, S. L. (2012). Nekotorye voprosy poligradientnoj magnitnoj separacii. Elektromehanichni i energozberigajuchi systemy, 1 (17), 31-36.

[7] Shvedchikova, I., Lutsenko, I., Romanchenko, Yu. (2015). A study ofpolygradient media structure regularities. Eastern-European Journal of Enterprise Technologies, 4 (7 (76)), 62-67. doi: 10.15587/17294061.2015.47785

[8] Shvedchikova, I. O., Romanchenko, Yu. A. (2016). Genetychne modeljuvannja ta syntez novyh struktur poligradijentnyh matryc' magnitnyh separatoriv. Elektromehanichni i energozberigajuchi systemy. Shhokvartal'nyj naukovo-vyrobnychyj zhurnal, 2 (34), 17-24.

[9] Shinkarenko, V. F., Zagirnyak, M. V., Shvedchikova, I. A. (2010). Structural-Systematic Approach in Magnetic Separators Design. Studies in Computational Intelligence, 201-217. doi: 10.1007/978-3642-16225-1_11

[10] ELCUT. Available at: http://elcut.ru/ 